\title{
Optimización de una técnica de PCR convencional para detección de virus de papiloma humano tipo 16 y 18
}

\author{
Laura Elena Bernal Aguirre ${ }^{1}$, Pamela Esther Mongelós Dacunte ${ }^{2}$, Tania Mabel Alfonzo Salinas ${ }^{1}$, Fátima \\ Cardozo $^{2}$, * Laura Patricia Mendoza Torres ${ }^{2}$ \\ Universidad Nacional de Asunción, Facultad de Ciencias Químicas. Paraguay \\ Universidad Nacional de Asunción, Instituto de Investigaciones en Ciencias de la Salud, Departamento Salud \\ Pública. Paraguay
}

Cómo referenciar este artículo/ How to reference this article:
Bernal Aguirre LE, Mongelós Dacunte PE, Alfonzo Salinas TM, Cardozo F, Mendoza Torres LP. Optimización de una técnica de PCR convencional para detección de virus de papiloma humano tipo 16 y 18. Mem. Inst. Investig. Cienc. Salud. 2018; 16(3): 6-12

\section{R E S U M E N}

El cáncer de cuello uterino es el segundo cáncer femenino más común a nivel mundial. El agente causal es el virus de papiloma humano (VPH). Se han identificado 13 tipos de virus de papiloma humano de alto riesgo oncogénico (VPH-AR), entre los cuales el VPH 16 y VPH 18 son los más frecuentemente detectados en cáncer de cuello uterino, siendo en Paraguay detectados en el $70 \%$ de casos de cáncer invasor. Por ello, el objetivo fue estandarizar y determinar el límite de detección de una técnica de PCR convencional para la detección de VPH 16 y 18. Para la detección de ADN de VPH 16 y 18, se observaron mejores resultados con $2 \mathrm{mM}$ de $\mathrm{MgCl}_{2}$ y $60^{\circ} \mathrm{C}$ para la temperatura de alineamiento. El límite de detección para las PCR fue de $14,6 \times 10^{-11} \mathrm{ng} / \mu \mathrm{L}$ para VPH 16 y $21,7 \times 10^{-12} \mathrm{ng} / \mu \mathrm{L}$ para VPH 18 . Este trabajo servirá de base a otros estudios de detección e identificación de estos tipos virales por PCR, con miras a identificar un grupo de mujeres positivas para VPH-AR que poseen mayor riesgo de desarrollo de lesión y cáncer de cuello uterino y precisan de un seguimiento más cercano.

Palabras clave: Cáncer de cuello uterino, VPH 16, VPH 18, PCR.

\section{Optimization of a conventional PCR technique for detection of human papillomavirus type 16 and 18}

\section{A B S T R A C T}

Cervical cancer is the second most common female cancer worldwide. It is caused by the human papilloma virus (HPV). Thirteen genotypes of high oncogenic risk human papilloma viruses (HPV-HR) have been identified, among which types 16 and 18 are the most frequently detected in cervical cancer. In Paraguay, they are detected in $70 \%$ of the invasive cancer cases. Therefore, the objective was to standardize and determine the detection limit of a conventional PCR technique for the detection of HPV 16 and 18. Better results were observed with $2 \mathrm{mM} \mathrm{MgCl}$ and $60^{\circ} \mathrm{C}$ for the alignment temperature in detection of HPV 16 and 18 DNA. The limit of detection was $14.6 \times 10^{-11} \mathrm{ng} / \mu \mathrm{L}$ for HPV 16 and $21.7 \times 10^{-}$ ${ }^{12} \mathrm{ng} / \mu \mathrm{L}$ for HPV 18 . This work will help other studies for the detection and identification of these viral types by PCR in order to identify a group of HPV-HR positive women who have higher risk for the development of lesions and cervical cancer and need a closer follow-up.

Keywords: Cervical cancer, HPV 16, HPV 18, PCR.

\section{INTRODUCCIÓN}

El virus de papiloma humano (VPH) es un virus ADN de doble hebra, su genoma posee aproximadamente 8000 pares de bases y en él se diferencian tres regiones: 
1. La región reguladora larga (LCR) la cual es no codificante y posee secuencias que controlan la trascripción y replicación viral, ya que posee elementos cis necesarios para la replicación y transcripción del ADN viral ${ }^{(1)}$.

2. La región temprana $E$, que codifica para las proteínas E1, E2, E4, E5, E6 y E7, involucradas en múltiples funciones como transcripción, replicación y transformación celular. Las oncoproteínas E6 y E7 crean inestabilidad genómica e interfieren en vías de proteínas supresoras de tumores ${ }^{(2)}$.

3. Y la región tardía $L$, que codifica para las proteínas estructurales $L 1$ y $L 2$ las cuales forman la cápside viral y participan en el ensamblaje del ADN viral. Las proteínas L1 y L2 se ensamblan en capsómeros para dar lugar a la cápside de forma icosaédrica que contiene el genoma viral ${ }^{(1,3)}$.

Actualmente se han descrito más de 150 tipos de VPH, de los cuales aproximadamente 50 infectan la mucosa genital. Los VPH de tropismo mucoso se clasifican en tipos de 'alto' (VPH-AR) y 'bajo' (VPH-BR) riesgo oncogénico, siendo los de bajo riesgo los causantes de lesiones benignas y los de alto riesgo los causantes de lesiones que pueden progresar a tumores malignos ${ }^{(4-7)}$.

Los genotipos incluidos en el grupo de virus de alto riesgo oncogénico son 16, 18, 31, 33, $35,39,45,51,52,56,58,59$ y 68 . Esta clasificación obedece a su relación con el desarrollo de neoplasia intraepitelial cervical (CIN). Estudios previos han demostrado que los tipos 16 y 18 son los genotipos de alto riesgo más frecuentemente detectados en cáncer cervical; en aproximadamente el $50 \%$ y $20 \%$ de casos, respectivamente ${ }^{(3,4,8,9)}$.

La infección persistente puede dar lugar a una lesión intraepitelial escamosa de bajo grado (LSIL) y ésta conducir a una lesión intraepitelial escamosa de alto grado (HSIL) y cáncer en un promedio de 5 a 14 años si no se detectan y se tratan. Es importante el tipo viral, ya que la persistencia viral constituye un factor de riesgo clave para el desarrollo de lesiones de alto grado y cáncer. La persistencia está genéticamente determinada y guarda relación con la patogenicidad ${ }^{(3,10)}$. Sin embargo, la progresión a cáncer ocurre solo en un pequeño porcentaje de mujeres infectadas, ya que la mayoría elimina la infección en 1-2 años $^{(11)}$.

A nivel mundial se registraron aproximadamente 528.000 casos nuevos de cáncer de cuello uterino y 266.000 muertes en $2012^{(12)}$. En Paraguay un estudio realizado en el 2012 por Kasamatsu et al. observó en 432 casos de cáncer cervical, una frecuencia de $64,6 \%$ de VPH 16 , seguido de $8,5 \%$ por VPH 18 y $5,4 \%$ de VPH $45^{(13)}$.

Sin embargo, debido a que la mayoría de pruebas de VPH basadas en ADN tienen un bajo valor predictivo positivo para detección de CIN2 o más, se debe identificar a las mujeres en riesgo de desarrollar una infección persistente o lesión precursora de cáncer mediante pruebas de triage para evitar la sobrecarga al sistema de salud y la carga emocional que representa para la mujer ${ }^{(14)}$.

Debido a esto, se diseñó este estudio con el objetivo de estandarizar y determinar el límite de detección de una técnica de PCR convencional para la detección de VPH 16 y 18 que puede ser utilizada como triage con miras a su implementación en servicios de salud y para orientar el manejo clínico de mujeres positivas para VPH-AR.

\section{MATERIALES Y MÉTODOS}

Para la optimización de las PCR se utilizaron controles positivos de VPH 16 y VPH 18 provenientes del biobanco del Departamento de Salud Pública (IICS-UNA), previamente tipificados en estudios anteriores (14INVO36, P11/2010). Fueron utilizados controles puros y diluidos.

Para la extracción de ADN viral de los controles positivos se utilizó el kit comercial AccuPrep $\AA$ Genomic DNA Extraction Kit (Bioneer, Corea) siguiendo las instrucciones del fabricante. EI ADN extraído fue almacenado a $-20^{\circ} \mathrm{C}$ hasta su procesamiento.

\section{Optimización de PCR para VPH 16 y VPH 18}

La detección del genoma de VPH 16 y VPH 18 se realizó amplificando un fragmento de la región LCR de controles positivos a través de reacciones de PCR descriptas por Ho et al. en 1991 para VPH 16, y Ong et al. en 1993 para la detección de VPH 18. Se utilizaron los primers $16 a / 16 \mathrm{~b}$ para VPH 16 , y $18 \mathrm{a} / 18 \mathrm{~b}$ para VPH 18 , que amplifican un fragmento de 364 pares de bases y 320 pares de bases, respectivamente ${ }^{(15,16)}$ (Tabla 1$)$. 
Tabla 1. Secuencias de los primers $16 a / 16 b$ y $18 a / 18 b$ utilizados para las reacciones de PCR

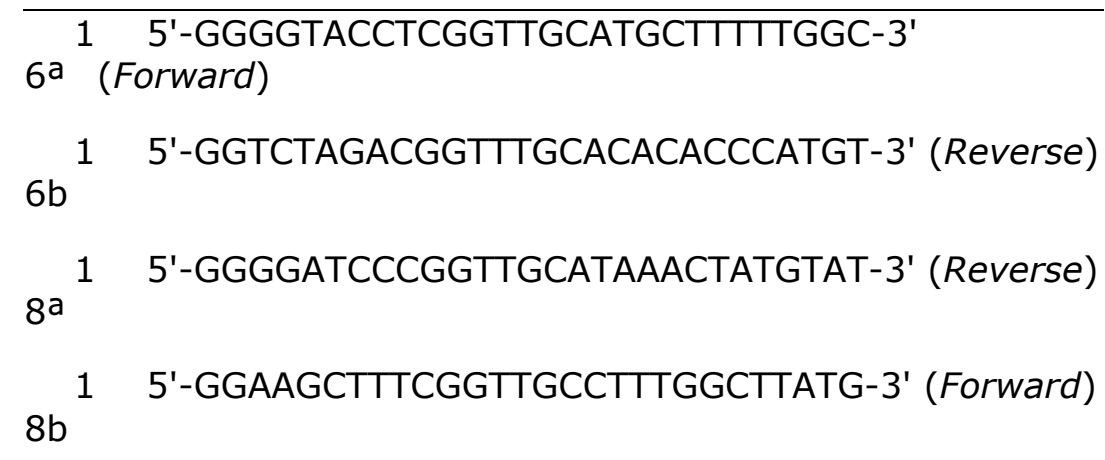

Cada tubo de reacción contenía $2 \mu \mathrm{L}$ de buffer 10x, 1,6 $\mu \mathrm{L}$ de $\mathrm{MgCl} 225 \mathrm{mM}, 1,6 \mu \mathrm{L}$ de dNTPs 2,5 mM, $1 \mu \mathrm{L}$ de cada primer $16 \mathrm{a} / 16 \mathrm{~b}$ ó $18 \mathrm{a} / 18 \mathrm{~b}, 0,17 \mu \mathrm{L}$ de Taq polimerasa $5 \mathrm{U} / \mathrm{L}$ (Thermo Scientific, EEUU), 9,63 $\mu \mathrm{L}$ de agua libre de Nucleasa (Thermo Scientific, EEUU) y 3 $\mu \mathrm{L}$ del control positivo para VPH $16 \circ \mathrm{VPH} 18$, para un volumen final de $20 \mu \mathrm{L}$. Las condiciones de termociclado fueron 40 ciclos de 3 minutos a $94{ }^{\circ} \mathrm{C}$, luego $94{ }^{\circ} \mathrm{C}$ por 1 minuto, $65^{\circ} \mathrm{C}$ por 1,5 minutos y $72{ }^{\circ} \mathrm{C}$ por 2 minutos, un paso final de 5 minutos a $72{ }^{\circ} \mathrm{C}$.

La presencia del genoma del VPH se visualizó por electroforesis en gel de poliacrilamida teñido con nitrato de plata según el protocolo establecido por Sanguinetti et al., 1994. En cada corrida electroforética se utilizó un marcador de peso molecular 50 pares de bases (Thermo Scientific, EEUU) $^{(17,18)}$.

Bajo estas condiciones se probó la reacción a tres concentraciones distintas de $\mathrm{MgCl}_{2}$ : a $1,5 \mathrm{mM} ; 2,0 \mathrm{mM}$ y $2,5 \mathrm{mM}$. Para determinar la temperatura de alineamiento, se probó la reacción a 60 y $65^{\circ} \mathrm{C}$.

\section{Determinación del límite de detección}

Posterior a la optimización de las PCR se determinó el límite de detección de las reacciones utilizando un control positivo de $\mathrm{VPH} 16$ de $14,6 \mathrm{ng} / \mu \mathrm{L}$ y un control positivo de VPH 18 de 21,7ng/ $\mu \mathrm{L}$. Se prepararon diluciones seriadas con factor de dilución de 10 . Se seleccionaron las diluciones de $10^{-5}$ a $10^{-12}$ del control VPH 16 y, de $10^{-6}$ a $10^{-13}$ del control VPH 18, a fin de determinar hasta que título es detectable el genoma viral.

Todas las diluciones de los controles fueron sometidas a PCR por triplicado y posterior electroforesis. Se obtuvieron tres geles mediante los cuales determinó el límite de detección para cada tipo de $\mathrm{VPH}$, concordando al menos dos de ellos en la última dilución en la que se detectó producto.

\section{RESULTADOS}

\section{Optimización de PCR para VPH 16 y VPH 18}

En relación a la concentración de $\mathrm{MgCl}_{2}$, para el control VPH 16 puros se observaron bandas a las tres concentraciones analizadas. Con el control diluido sólo se observaron bandas a 2 y $2,5 \mathrm{mM}$. Sin embargo, se optó por utilizar la concentración final de $2 \mathrm{mM}$ ya que se obtuvieron bandas nítidas tanto con el control puro como diluido.

Para el control VPH 18 puro se observaron bandas a 2 y $2,5 \mathrm{mM}$, mientras que el control diluido sólo presentó banda a 2,0mM. Por lo tanto, se optó por utilizar la concentración final de $2 \mathrm{mM}$. Estos resultados se aprecian en la Figura 1. 
1

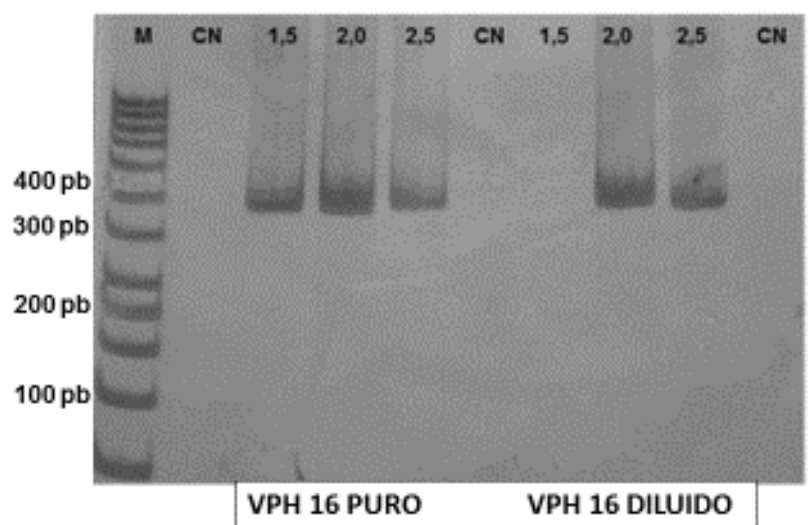

2

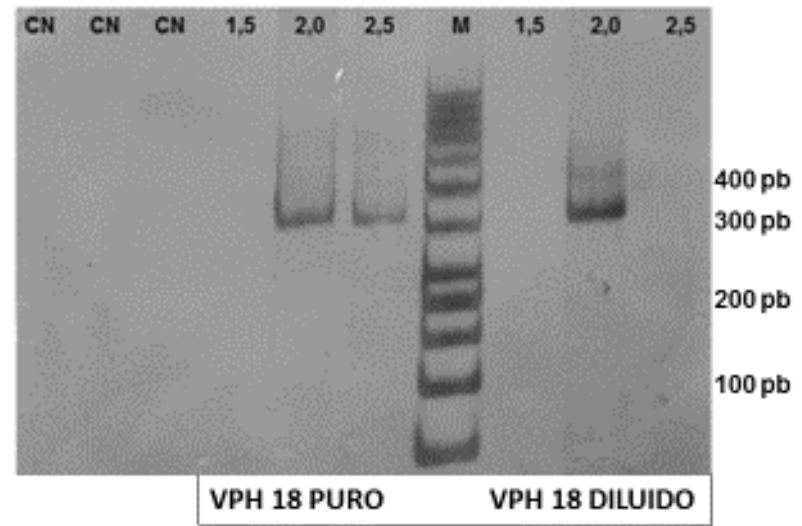

Figura 1. Electroforesis en gel de poliacrilamida al $5 \%$ de los productos amplificados para la región LCR de VPH 16 y 18 a distintas concentraciones de $\mathrm{MgCl}_{2}$. (M) Marcador de 50 pares de bases. (CN) Control negativo. $(1,5)$ Control a $1,5 \mathrm{mM}$ de $\mathrm{MgCl}_{2} \cdot(2,0)$ Control a $2,0 \mathrm{mM}$ de $\mathrm{MgCl}_{2}$. $(2,5)$ Control a 2,5 $\mathrm{mM}$ de $\mathrm{MgCl}_{2}$.

En cuanto a la temperatura de alineamiento, se probaron las reacciones a $60^{\circ} \mathrm{C}$ y $65^{\circ} \mathrm{C}$. En la Figura 2 se observan los productos de amplificación de VPH 16 y VPH 18 a $60^{\circ} \mathrm{C}$ y $65^{\circ} \mathrm{C}$, respectivamente. Con la primera temperatura analizada se observaron bandas nítidas tanto para el control de VPH 16 como para el control de VPH 18 , mientras que a $65^{\circ} \mathrm{C}$ solo se visualizó una banda tenue correspondiente al control VPH 16 puro. Con base en esto se optó por la temperatura de $60^{\circ} \mathrm{C}$ en ambas reacciones.

1

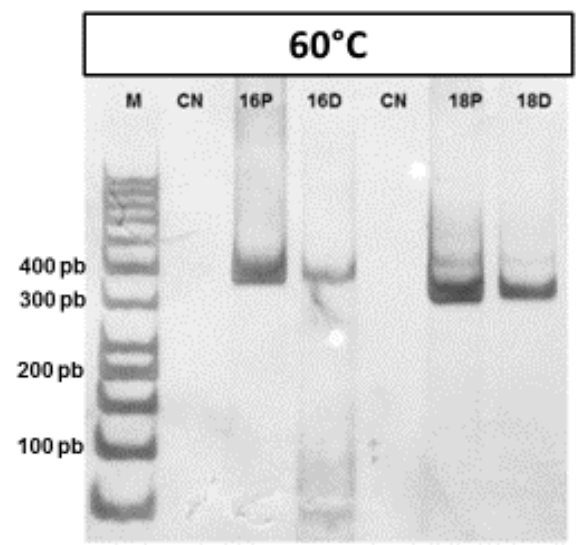

2

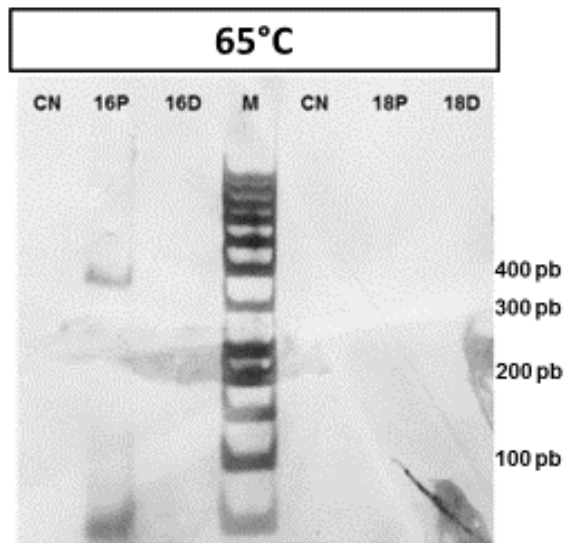

Figura 2. Electroforesis en gel de poliacrilamida al $5 \%$ de los productos amplificados para la región LCR de VPH 16 y 18 a 60 y $65^{\circ} \mathrm{C}$. (M) Marcador de 50 pares de bases. (CN) Control negativo. (16P) Control VPH 16 puro. (16D) Control VPH 16 diluido. (18P) Control VPH 18 puro. (18D) Control VPH 18 diluido.

\section{Límite de detección}

En relación al límite de detección para VPH 16, en la Figura 3 se observa un resultado positivo hasta la dilución $10^{-11}$, es decir, hasta $14,6 \times 10^{-11} \mathrm{ng} / \mu \mathrm{L}$. 


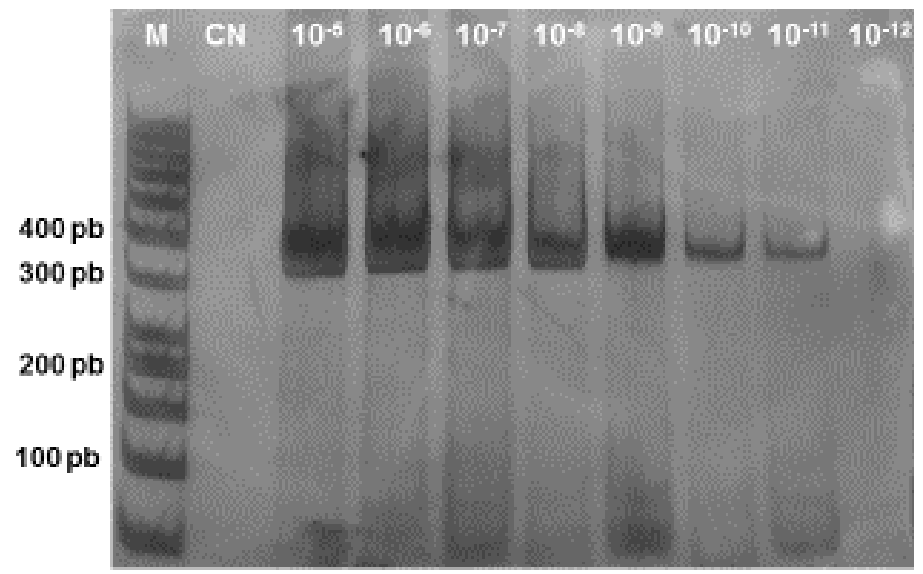

Figura 3. Límite de detección para PCR VPH 16. Electroforesis en gel de poliacrilamida al $5 \%$ de los productos amplificados para la región LCR de VPH 16. (M) Marcador de 50 pares de bases, (CN) Control Negativo. Carriles 3 al 10: diluciones del control positivo de VPH 16 desde $10^{-5}$ al $10^{-12}$ (ensayo realizado por triplicado).

Para el control VPH 18 , se observó resultado positivo hasta la dilución $10^{-12}$, es decir hasta $21,7 \times 10^{-12} \mathrm{ng} / \mu \mathrm{L}$. Estos resultados se observan en la Figura 4.

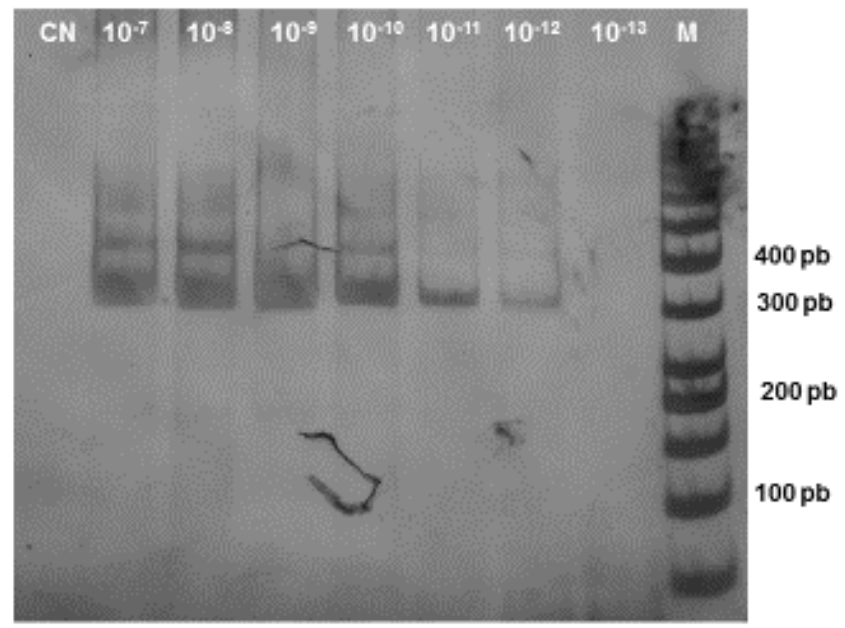

Figura 4. Límite de detección para PCR VPH 18. Electroforesis en gel de poliacrilamida al $5 \%$ de los productos amplificados para la región LCR de VPH 18. (CN) Control Negativo. Carriles 2 al 9: diluciones del control positivo de VPH 18 desde $10^{-7}$ al $10^{-13}$. (M) Marcador de 50 pares de bases (ensayo realizado por triplicado).

En la Tabla 2 se encuentran resumidas las condiciones de PCR optimizadas.

Tabla 2. Condiciones de PCR optimizadas

\begin{tabular}{lcc}
\cline { 2 - 3 } & $\mathrm{VPH}$ & 16 \\
\cline { 2 - 3 } Concentración de $\mathrm{MgCl}_{2}(\mathrm{mM})$ & 2 & 2 \\
Temperatura de Alineamiento $\left({ }^{\circ} \mathrm{C}\right)$ & 60 & 60 \\
Límite de detección & $10^{-11}$ & $10^{-12}$ \\
\hline
\end{tabular}

\section{DISCUSIÓN}

Las infecciones persistentes por VPH-AR constituyen un factor de riesgo importante para el desarrollo de cáncer cervical ${ }^{(11)}$. En Paraguay, se observó una alta frecuencia de casos de cáncer invasor positivos para los genotipos 16 y $18^{(13,19)}$. En este estudio se estandarizó y 
se determinó el límite de detección de una técnica de PCR convencional para la detección de VPH 16 y 18.

En ambas reacciones de PCR se optó por utilizar una concentración final de $\mathrm{MgCl}_{2}$ de 2 $\mathrm{mM}$ ya que se observaron bandas más nítidas. Esta concentración difiere de la reportada por Tornesello et al., 2000 (20), donde se utilizó 2,5 mM para VPH 16 mientras que Ariaspulido et al., 2005(21) reportan $2,5 \mathrm{mM}$ en la amplificación de VPH 18.

En relación a la temperatura de alineamiento, la seleccionada fue de $60^{\circ} \mathrm{C}$ para ambas reacciones. Este resultado concuerda con la temperatura de alineamiento calculada en base al porcentaje de $\mathrm{G}+\mathrm{C}$ y $\mathrm{A}+\mathrm{T}$ de los primers, la cual fue de $61^{\circ} \mathrm{C}$ para VPH 16 y de $57^{\circ} \mathrm{C}$ para VPH $18^{(17)}$. Esto difiere de lo reportado por Tornesello et al. ${ }^{(20)}$ para VPH 16 , y Arias-pulido et al. ${ }^{(21)}$ para VPH 18 , que reportan $55^{\circ} \mathrm{C}$ y $58^{\circ} \mathrm{C}$ respectivamente. Sin embargo Chow et al., 1990 reportaron $50^{\circ} \mathrm{C}$ para VPH 16 y $60^{\circ} \mathrm{C}$ para VPH $18^{(22)}$. Estos resultados sugieren que sería factible realizar una reacción multiplex con ambos, eventualmente.

Se observó un límite de detección de $14,6 \times 10^{-11} \mathrm{ng} / \mu \mathrm{L}$ para VPH 16 y de $21,7 \times 10^{-12} \mathrm{ng} / \mu \mathrm{L}$ para VPH 18. Estos resultados difieren de lo que reportan otros autores como Chow et al, $1990^{(22)}$ que obtuvieron un límite de detección de al menos 0,01 $\mu \mathrm{g}$ de ADN genómico de líneas celulares Si-Ha (VPH16) y C4-1 (VPH18). Lo que sugiere que las reacciones son capaces de detectar pequeñas cantidades de ADN viral. Las diferencias en estos resultados pudieron deberse a diferentes condiciones en que fue determinado el límite de detección ${ }^{(8)}$.

En conclusión, el presente estudio permitió optimizar una PCR convencional que permite detectar bajas concentraciones de VPH 16 y 18 y que podrá ser utilizada como una potencial prueba de triage, con miras a identificar mujeres VPH-AR positivas que poseen más riesgo de desarrollo de lesiones de cuello uterino y cáncer y precisan de un control más cercano.

\section{REFERENCIAS BIBLIOGRAFICAS}

1. International Agency for Research on Cancer, editor. IARC monographs on the evaluation of carcinogenic risks to humans, volume 90, Human papillomaviruses: this publication represents the views and expert opinions of an IARC Working Group on the Evaluation of Carcinogenic Risks to Humans, which met in Lyon, 15 - 22 February 2005. Lyon: IARC; 2007. $670 \mathrm{p}$.

2. Litwin $T$, Clarke $M$, Dean $M$, Wentzensen $N$. Somatic Host Cell Alterations in HPV Carcinogenesis. Viruses. 2017 Aug 3;9(12):206.

3. Burk RD, Chen Z, Van Doorslaer K. Human Papillomaviruses: Genetic Basis of Carcinogenicity. Public Health Genomics. 2009;12(5-6):281-90.

4. Yar DD, Salifu SP, Darko SN, Annan AA, Gyimah AA, Buabeng KO, et al. Genotypic characterisation of human papillomavirus infections among persons living with HIV infection; a case-control study in Kumasi, Ghana. Trop Med Int Health. 2016;21(2):275-82.

5. de Villiers E-M, Fauquet C, Broker TR, Bernard $\mathrm{H}-\mathrm{U}$, zur Hausen $\mathrm{H}$. Classification of papillomaviruses. Virology. 2004 Jun;324(1):17-27.

6. Graham S V. Europe PMC Funders Group Human papillomavirus: gene expression, regulation and prospects for novel diagnostic methods and antiviral therapies. 2012;5(10): 1493-506.

7. Pan American Health Organization. Integrating HPV Testing in Cervical Cancer Screening Programs. Washington, D.C.; 2016. 68 p.
8. Muñoz N, Bosch FX, de Sanjosé S, Herrero $R$, Castellasagué $X$, Shah $K$, et al. Epidemiologic Classification of Human Papillomavirus Types Associated with Cervical Cancer. N Engl J Med. 2003;51827.

9. Chinchai T, Chansaenroj J, Swangvaree S, Junyangdikul P, Poovorawan Y. Prevalence of Human Papillomavirus Genotypes in Cervical Cancer. Int J Gynecol Cancer. 2012 Jul;22(6):1063-8.

10. Radley D, Saah A, Stanley M. Persistent infection with human papillomavirus 16 or 18 is strongly linked with high-grade cervical disease. Hum Vaccin Immunother. 2016;12(3):768-72.

11. de Sanjosé S, Brotons M, Pavón MA. The natural history of human papillomavirus infection. Best Pract Res Clin Obstet Gynaecol. 2017;1-12.

12. Ferlay J, Soerjomataram I, Ervik M, Dikshit $\mathrm{R}$, Eser S, Mathers $\mathrm{C}$, et al. GLOBOCAN 2012 v1.0. Cancer Incidence and Mortality Worldwide: IARC CancerBase No 11. 2012;4.

13. Kasamatsu $E$, Cubilla $A L$, Alemany $L$, Chaux A, Tous S, Mendoza L, et al. Typespecific human papillomavirus distribution in invasive cervical carcinomas in Paraguay. A study of 432 cases. J Med Virol. 2012 Oct;84(10):1628-35.

14. Ronco G, Dillner J, Elfstrom M, Tunesi S, Snijders P, Arbyn M. Efficacy of HPV-based screening for prevention of invasive cervical cancer: follow-up of four European randomised controlled trials. Lancet. 2013;383(13):524-32. 
15. Ho L, Chan SY, Chow V, Chong T, Tay SK, Villa LL, et al. Sequence Variants of Human Papillomavirus Type-16 in Clinical-Samples Permit Verification and Extension of Epidemiologic Studies and Construction of a Phylogenetic Tree. J Clin Microbiol. 1991;29(9):1765-72.

16. Ong CK, Chan SY, Campo MS, Fujinaga K, Mavromara-Nazos P, Labropoulou V, et al. Evolution of human papillomavirus type 18: an ancient phylogenetic root in Africa and intratype diversity reflect coevolution with human ethnic groups. J Virol. 1993;67(11):6424-31.

17. Tm Calculator. Thermo Fisher Scientific [Internet]. Available from: https://www.thermofisher.com/py/en/hom e/brands/thermo-scientific/molecularbiology/molecular-biology-learningcenter/molecular-biology-resourcelibrary/thermo-scientific-web-tools/tmcalculator.html

18. Sanguinetti CJ, Dias Neto E, Simpson AJ. Rapid silver staining and recovery of PCR products separated on polyacrylamide gels. Biotechniques. 1994 Nov;17(5):914-21.
19. Mendoza LP, Arbiza J, Páez M, Kasamatsu $E$, Castro A, Giménez G, et al. Distribution of human papillomavirus genotypes in Paraguayan women according to the severity of the cervical lesion. J Med Virol. 2011 Aug;83(8):1351-7.

20. Tornesello ML, Buonaguro FM, Buonaguro L, Salatiello I, Beth-Giraldo E, Giraldo G. Identification and functional analysis of sequence rearrangements in the long control region of human papillomavirus type 16 Af-1 variants isolated from Ugandan penile carcinomas. J Gen Virol. 2000;81(12):2969-82.

21. Arias-Pulido $\mathrm{H}$, Peyton $\mathrm{CL}$, Torrez-martınez, Anderson DN, Wheeler CM. Human papillomavirus type 18 variant lineages in United States populations characterized by sequence analysis of LCR-E6. 2005;338:22-34.

22. Chow VTK, Tham KM, Bernard HU. Thermus aquaticus DNA polymerasecatalysed chain reaction for the detection of human papillomaviruses. 1990;27:10112. 